\title{
La influencia de fumar cigarrillos en la elección de pareja para una relación íntima y ocasional
}

\section{The influence of cigarette-smoking when choosing a partner for a casual, intimate relationship}

\author{
Isaac Amigo Vázquez*, María Alvarez Fernández*, Roberto Secades-Villa*. \\ * Departamento de Psicología. Universidad dc Oviedo.
}

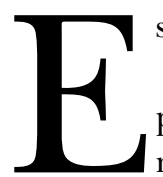

stimado Editor,

El estudio del efecto que fumar cigarrillos puede tener sobre las relaciones íntimas e informales es de gran interés, dado que puede resultar ser una herramienta útil en la prevención y el tratamiento del tabaquismo. Tradicionalmente, fumar cigarrillos se consideraba una herramienta útil para acercarse al otro sexo (Baek y Mayer, 2010). No obstante, en años recientes, campañas educativas y cambios legislativos pueden haber alterado la percepción del efecto del tabaco en la calidad y la salud de una relación de pareja.

El objetivo de este estudio es valorar si afecta las intenciones de mantener una relación íntima y ocasional el hecho que una pareja potencial sea, o no, fumador. También analizamos si sexo y edad influyen en la elección de una pareja esporádica.

Tuvimos 597 participantes (293 no-fumadores, 163 ex-fumadores y 141 fumadores). La edad media de la muestra total fue 26 años ( 25 años para fumadores y no-fumadores, y 28 años para ex-fumadores). Las edades estaban comprendidas entre los 16-68 años. Sesenta y dos por ciento eran mujeres y el $38 \%$ hombres. Cincuenta y nueve por ciento tenían estudios básicos secundarios, el 30\% habían terminado los estudios o eran universitarios, y el $11,4 \%$ eran titulados universitarios.

Usamos tres cuestionarios diferentes ad hoc para cada grupo de participantes. Incluyeron preguntas sobre sus características sociodemográficas y el efecto del tabaquismo al elegir una pareja para una relación íntima e informal. Los cuestionarios fueron aplicados vía Internet mediante el "método bola de nieve", usando Formularios de Google, y enviados a través de las redes sociales Facebook y WhatsApp. El cuestionario era completamente anónimo y la participación era voluntaria, tal como garantiza este método.

Los resultados mostraron que el 3,5\% de los fumadores, el 26,8\% de los ex-fumadores y el 41,6\% de los no-fumadores dijo que el hecho que otra persona fuese fumador(a) influiría de forma negativa en su decisión de iniciar una relación íntima e informal. El $11 \%$ de los fumadores, el $6,2 \%$ de los no-fumadores y el 9,1\% de los ex-fumadores dijo que preferiría un fumador para una relación informal e íntima. Hay diferencias estadísticamente significativas entre fumadores y no-fumadores $\left(\chi^{2}=66,72, \mathrm{p}<, 001\right)$, entre ex-fumadores y no-fumadores $\left(\chi^{2}=30,74, \mathrm{p}<, 001\right)$, y entre fumadores y ex-fumadores $\left(\chi^{2}=9,70, \mathrm{p}=, 002\right)$ respecto de su actitud negativa hacia una relación íntima e informal con un/a fumador/a. No se hallaron diferencias estadísticamente significativas $(p>, 05)$ al analizar las actitudes negativas hacia fumadores en relación a sexo y edad (mayor de y menor de 30 años).

Este estudio es el primero que analiza si el hecho que una persona sea fumador/a juega un papel en la probabilidad de que dicha persona sea elegida como pareja para una relación íntima e informal. Los resultados mostraron que, comparado con fumadores, los no-fumadores y ex-fumadores estaban menos dispuestos a mantener una rela-

Recibido: Enero 2018; Aceptado: Febrero 2018.

Enviar correspondencia a:

Isaac Amigo Vázquez. Facultad de Psicología. Universidad de Oviedo, Plaza Feijoo, s/n, 33003 Oviedo.

Email: amigo@uniovi.es 
ción informal e íntima con un/a fumador/a. Dicha actitud negativa hacia el tabaquismo fue similar entre sexo y edad diferentes. La preferencia por un/a fumador/a para tener una relación íntima e informal fue muy baja y similar en todos los grupos de participantes. Menos del $11 \%$ de los participantes prefería un/a fumador/a, incluso si uno mismo fumaba.

Respecto de los motivos dados por los no-fumadores y los ex-fumadores para justificar su actitud inicialmente negativa hacia tener una relación informal con un/a fumador/a, el 88,2\% indicó que lo que más le molestaba era el mal aliento, seguido del 78,7\% que mencionó el olor a tabaco, el 25\% que mencionó el humo de tabaco, y el $6 \%$ que mencionó tener que salir de un local para fumar.

Estos resultados destacan como el tabaquismo, durante muchos años considerado con cierto atractivo sexual, según ilustraba la publicidad (Baek y Mayer, 2010), en la actualidad aparentemente no solo empieza a perder este valor sino que, además, empieza a percibirse como un obstáculo para las relaciones íntimas. El tabaquismo ya no se considera atractivo. Motivos de higiene (olor del tabaco, mal aliento) y también razones sociales (tener que acompañar al fumador fuera del local para fumar) explican esta tendencia. Los resultados también mostraron que la reticencia a mantener una relación con un/a fumador/a era similar para hombres y mujeres.

Este estudio tiene implicaciones directas para la prevención y el tratamiento del tabaquismo. Es importante difundir este hallazgo entre los adolescentes, y el hecho que el tabaquismo obstaculiza una relación íntima e informal podría incorporarse a la lista de los inconvenientes asociados al tabaquismo.

Las limitaciones de este estudio fueron que la muestra estuvo limitada a mayores de 18 años, excluyó a adolescentes, y que el método de la bola de nieve no siempre garantiza suficiente representatividad muestral.

A pesar de dichas limitaciones, los resultados de este estudio muestran la existencia de otro argumento adicional que se puede emplear en la lucha contra el tabaquismo, basado en el posible rechazo que el tabaquismo empieza a generar respecto de iniciar una relación íntima e informal.

\section{Conflicto de intereses}

Los autores declaran la inexistencia de conflictos de intereses.

\section{Referencias}

Baek, T. H. y Mayer, M. (2010). Sexual Imagery in Cigarette Advertising Before and After the Master Settlement Agreement. Health Communication, 25, 747-757. doi:10.1 080/10410236.2010.521917. 